\title{
Ableism and the Reception of Improvised Soundsinging
}

\section{CHRIS TONELLI}

\section{February 7, 2014:}

In the stately environs of the Debates Room of University of Toronto's Hart House, in the selfserious context of a symposium on the "long poem" in Canada, a mix of literature students and professors, poets, and publishers have gathered for the poetry reading that will conclude the event. The first speakers are just that-speakers—in that the poems they read are composed entirely of words which they will read out loud: they take the podium, start reading pre-composed sequences of words into the microphone, rendering those sequences into speech, and they continue to do so until they relinquish the podium, interrupted only by short spoken comments they improvise between these sequences of formal reading/speaking. Then a break. We eat shrimp and mingle before being called back for what many must have expected would be more speaking. Sure enough, more speaking; the first ten minutes of this final set consist of more poems, more words, more speech.

I often seek a seat at the back of performance spaces, where I can watch audiences listen. On this occasion, as is usual, most of the bodies stay relatively motionless, undemonstrative. However, at one point, three bodies seem to speak. All three are young, likely from the contingent of students represented in the room. After the first four poems of the set, a fifth poem begins with one quick wordless ingressive vocal punctuation followed by a sustained wordless inhalation whose complex band of pitch material and noise rise gradually before the next pause for breath. The first body language I notice begins with visible and audible laughter by a scruffy young man in a hoodie. After laughing, he begins to nod and then leans forward, closer to the poet. A few rows forward, off to his left, as the first young man leans forward, a young woman has leaned back, her eyes widening in a look of surprise. This posture of surprise, fascination, or shock is followed by laughter. The first young man stays fairly still after his initial hearty laugh; he is now bent forward with calm attention. Here and there he releases a chuckle or nod, but his forward stance persists and, like his nodding, I read it as a demonstration of approval. The young woman keeps laughing throughout much of the five-minute-long poem; she turns to share her laughter with the young woman to her left and then turns to the right to perform her surprise to the young man with his hand around her back. Her laughter persists to a point that begins to make me uncomfortable; it seems to shift from pure surprise to punitive laughter.

As the poet continues exploring wordless inhalations, esophageal pseudo-speech, cheek-based airflow modulation, and other abstract unconventional vocal sounds, another young man catches my eye. This third young person doesn't lean forward or back, but seems to get taller. He squints his eyes and opens his mouth slightly. He lacks the ubiquitous five o'clock shadow and subcultural hairstyles of most of the young men in the room. He wears a crew cut, an expensive-looking sweater, and his facial expression moves from perplexed to stern. At around the point the young woman's laughter seems to me to be shifting from surprise to either mockery or a nervous coping gesture, the stern young man 
drops his chin to his chest and stares at the ground for a while. Then he yawns. He then sits up erect again, strokes his cheek with his hand, and turns with intention towards another young man to his left with his mouth agape and a dead stare. His friend turns his hands up in a gesture that reads to me as dismissal and then looks at the floor. Then he yawns too.

The poet provoking these reactions was Paul Dutton. Dutton is a poet and soundsinger. His work blurs the borders between music and poetry and he works within music-centered and poetry-centered contexts in roughly equal measure. When he performs pieces like the one described above, which was one of his Imp's Roves, a series of entirely improvised works wherein he attempts to begin the improvisation with a sound that surprises him rather than a preconceived sound, listeners often refer to the "extended vocal techniques" he employs.

\section{Example 1: Paul Dutton performs Imp's Rove \#116 \\ View at: http://dx.doi.org/10.3998/mp.9460447.0010.204}

However, Dutton rejects that term. In the mid to late 1990s he coined the term soundsinging as a more accurate and preferable alternative. ${ }^{1}$ Primarily, he takes issue with the older term's privileging of the "vocal." He points to the fact that his work involves a range of "nonvocal sounds such as tongue pops, lip-smacks, tooth grinding, saliva swishing, tooth-rubbing, lip-flubbing, and a wealth of other totally nonvocal effects." ${ }^{2}$ He takes issue as well with the emphasis on "technique," stating: "With that term, then what are we - extended vocal technicians? I'm an artist, not a technician." 3 Further, the notion of "extension" privileges dominant forms of singing (e.g., operatic singing) by positioning them as a core from which one must "extend" to employ less conventional sounds. With a singer like Dutton, this is not the case; less conventional abstract vocal and non-vocal oral sounds are as central to his work in poetic contexts as conventional speech and they are undoubtedly more central to his work in musical contexts than any form of conventional singing.

Despite the seeming closeness of the terms soundsinger and the more widespread sound poet, it is useful to note that Dutton usually chooses not to identify with the latter. Though he does refer to certain of his poems as "sound poems," he has refused to be referred to as a "sound poet," explaining that he "won't have it. As far as I'm concerned a poet does poetry." have the entirety of his work reflected by a term that might apply only to part of it, and it rejects efforts to position poetry and sound poetry as potentially oppositional terms that might exclude poets that work with sound poetry from the honorific sense of the term poet. Similarly, and much for the same reasons, other singers who have been known to engage in improvisation with nonstandard sounds have opted not to identify with the term soundsinging, insisting that what they do is simply a form of singing. Therefore, any effort to mark their practice with alternative terms risks reducing and marginalizing their practices by distancing them from the honorific sense of the term singer. To be clear, the practices of many of these singers involve both conventional and unconventional forms of singing, and, like Dutton,

\footnotetext{
${ }^{1}$ For more on the genesis of the term soundsinging, see Sutherland, 2014.

${ }^{2}$ Paul Dutton, e-mail message to the author, March 8, 2014. I am grateful to Paul Dutton for reading an early draft of this article and offering comments and corrections.

${ }^{3}$ Paul Dutton, e-mail message to the author, July 18, 2004.

${ }^{4}$ Paul Dutton, spoken comments during the Hart House reading.
} 
they feel uncomfortable identifying with a term that represents the whole of their practice by referring only to part of it, even if that part (nonstandard singing) represents the bulk of what they do.

As both a music scholar and a practitioner of soundsinging, I personally feel the need for a term capable of distinguishing this form from dominant forms of singing wherein melody and the production of "pure" pitch content predominate. I will argue here that at one level of their symbolic functions dominant singing and soundsinging practices do very different kinds of work. Without a term capable of referring to the body of vocal and nonvocal oral sounds being employed by the singers I will discuss in this article, my argument could hardly proceed. This argument is, I hope, of greater benefit to (sound)singers than any harm that might be caused by further dissemination of the term soundsinging. It is an argument that addresses troubling reactions I have frequently witnessed at my own soundsinging performances and at those of other singers. The reactions I will theorize reveal that while the term soundsinging may suggest to some that soundsingers are non-singers, a deeper process is already at work making those types of judgments prevalent regardless of the presence of the term.

In this article, I examine the processes of valuation that subtly guide the performative behaviors of audience members like the ones I discuss above. My intention is to render audible certain ideologies that shape our reactions to voices. Though processes of valuation are inaudible in themselves, we can, as in the anecdote above, detect their presence in bodies and actions. Our readings of the meanings of these actions do risk being inaccurate. However, leaving these actions unobserved and uninterpreted may pose a greater risk, as it willfully surrenders information that may be our only access to evaluative processes that can come to have substantial effects on our lives and practices. By focusing on valuations of and perceptible reactions to soundsinging, we can come to understand much about the symbolic work that is achieved by this distinctive vocal practice and by the more dominant forms of singing that are naturalized as "proper" in aesthetic hierarchies.

My method here will resemble my opening anecdote in that my argument will unfold from a close reading of social situations that accrue around Dutton's work. I will unpack and theorize a reaction Dutton recounted to his audience at his reading at Hart House on the evening I describe above. My choice to devote such deep attention to a single reaction emerges not from the unique qualities of that reaction, but, rather, from the qualities that reaction shares with others $I$ have encountered as a soundsinger or that other vocalists have mentioned to me casually or as part of formal interviews I have conducted. Like Dutton, many singers whose work might partially or entirely be considered soundsinging occupy two or more distinct art worlds: Jaap Blonk and Tomomi Adachi also have one foot in the (sound) poetry world and one in musical free jazz/improvisation; Anna Homler is a visual artist, a performance artist, and a musician; Maggie Nicols and Shelley Hirsch have worked both as improvising musicians and in theater; Makigami Koichi performs both in free jazz/improvisation contexts and in the world of experimental rock; Christine Jeffrey worked both as a sculptor and an improvising vocalist; Jeanne Lee worked with traditional jazz, free jazz/improvisation, and performance poetry, and the list goes on. ${ }^{5}$ One intriguing aspect of this is that it ensures that events like the Hart House reading happen often, events wherein the audience is composed of members with associations with a variety of art worlds, events where audience members encounter unconventional vocal material without expecting it. It is clear to me, as someone who has been soundsinging for over a decade now,

${ }^{5}$ I discuss and contextualize the work of these singers in greater detail in my forthcoming book Soundsinging: Unconventional Vocal Music and the Problem of the Human. 
that soundsinging affects certain audience members in powerful ways, both in first encounters with the music and in more sustained engagements. In the years since I began soundsinging, and in the last two years, during which I have been engaged in fieldwork in musical improvisation communities in Los Angeles, Chicago, Ottawa, Montreal, Toronto, and New York, many soundsingers have told me stories of audiences responding with punitive words or actions, experiencing profoundly enlivening feelings, imitating their performances in both mocking and exploratory manners, and expressing disdain at the incomprehensibility of the practice. The performative body language I recount in my opening anecdote is often a precursor to other behaviors or speech acts_-some of which I will discuss below_that directly engage the performer and communicate a negative or positive valuation. These incidents have caused me to wonder: What characteristics do listeners need to possess for them to react in an enthusiastic, animated manner? Conversely, what factors inspire other listeners to have such negative reactions that they feel compelled to discourage or police soundsingers? What is soundsinging doing to provoke such strong positive and negative reactions? And what kinds of cultural and political effects does soundsinging engender?

In a way, these questions are reductive; they imply the real work of soundsinging is to be found in the more extreme feelings and behaviors it affords rather than the more standard and measured kinds of judgments and affordances normally brought to bear on improvisatory music or new music practices. However, I have been so deeply troubled by some of these more extreme reactions that I feel a critical imperative to make their theorization take precedence over discussions of more moderate reactions. In developing my theorization, I have discovered that the field of disability studies offers a valuable conceptual framework for understanding these reactions as attempts to restore a symbolic order violated by soundsinging. The reactions that have troubled me often invoke a dehumanizing rhetoric essentially similar to rhetoric encountered by many who identify as or are considered to be disabled. Examining, in a fine-grained way, audience reactions to soundsinging reveals many instances of ableist behavior, including pronouncements of others as animalistic or less than human; marking of the differently-abled as incapable and untalented; and casting the rational and instrumental as ideal categories to which certain others have no access.

Theorists in the field of disability studies have acknowledged that ableism is tied to the broader ideological construct of modernity. In what follows, I will consider both of these constructs and their relation. By employing work from disability studies rather than considering the broader construct of modernity exclusively and directly, I hope to better illustrate how various localized manifestations of the ideologies of modernity relate to and resemble one another. I will argue that language shared between disparaging reactions to soundsinging and to bodies perceived as disabled points to a broader symbolic mechanism at work between reactions to both spheres. Disability studies offers a framework for understanding the threat posed to this symbolic order by both bodies perceived as disabled and by voices that operate beyond dominant vocal norms. Both threaten a symbolic order that depends fundamentally on a logic of exclusion that exists to provide existential comfort to some at the expense of radically complete notions of human solidarity.

Bill Hughes begins his chapter "Civilising Modernity and the Ontological Invalidation of Disabled People" with the following passage:

Elimination and/or correction have been the primary social response to disabled people in modernity. The primary form of experience (of disability) during the same period, has been one of invalidation. Invalidation carries a "dual meaning" as both "confinement through 
incapacity" and "deficit of credibility" (Hughes, 2000: 558). This (latter and more crucial) claim is based on the view that in the non-disabled imaginary disability is an "ontological deficit"-a reduction of "leib" to "korpor," human to animal, subjectivity to flesh, identity to excessive corporeal presence... the treatment of disabled people in the modern period is a barbaric sideshow in the long march of the "civilising process" (Elias, 2000). The "personality structure" ableism (see Kumari Campbell (2001) and in this volume) in modernity transforms its own ontological precariousness into aversion for and disposal of disability. The negative response to biological and intellectual difference in modernity is strongly influenced by the tendency embedded in the "civilising process" to incrementally deride the value of physical and intellectual difference and promote a sanitised norm of human behaviour and appearance. ${ }^{6}$

Of course, central to the ideology of modernity is the binary of past/present and the function of marking aspects of the present as inadequately reflective of the present, as somehow belonging more to the past when compared to other "modern" aspects. Hughes demonstrates how the structure of modernity involves the imbrication of a number of binaries: a civilized/uncivilized binary comes to color the present/past binary, to help create a reified divide between human and animal that links humanness to the present, the modern, and the civilized, and animal to the past, the anachronism, and the uncivilized. Recent scholarship on the origins of modernity has linked its emergence to the need for state legitimation during the $16^{\text {th }}$ Century imperial partitioning of the New World by European powers. John Carlos Rowe explains that the "expulsion of 'heathen' Moors from Iberia and the 'discovery' of 'primitive' peoples in Africa, the Western Hemisphere, and subsequently around the globe provided economic and ideological means of legitimating fledgling states, like Portugal and Spain and England, whose royal sovereignties would lay the foundations for their subsequent nations." ${ }^{7}$ Rowe, following the work of Rodolfo Kusch, Enrique Dussel, Edmundo O'Gorman, Walter Mignolo, and Lindon Barrett, argues that these racialized narratives of primitivism in the context of European expansionism were generative of the ideology of modernity. Notions of racial difference took on a temporal distinction and subsequently an ontological deficit was projected upon the "primitives" and "heathens" that fueled legitimizations of the reality, boundedness, and necessity of the state. Bodies that came to be understood as "white" in the racial logic of the present came to be positioned on the present/civilized/modern/human side of the imbricated binaries of modernity and non-white bodies marked as anachronistic/uncivilized/primitive/animal.

Hughes' opening passage points us towards another of the binaries essential to modernity: the leib/körper binary, the division between animated bodies and mere or dead flesh. Essential to understanding the dehumanizing effects of the logic of modernity is understanding how the various binaries it activates exist in a network. In that network, these binaries spill over into and shape one another. Civilized/uncivilized's proximity to modern/primitive in that network, for instance, associates being civilized with being modern. Though most of these binaries emerge from pure reification, others, like leib/körper, are relatively concrete dualities. However, this spillage can push us to apply these concrete binaries in ways that exceed their authority. Hughes points to uses of the leib/körper binary that do not divide living and dead flesh, but that divide living bodies from other living bodies in a hierarchy that problematically posits some life as akin to dead flesh. Modernity as a process functions primarily to manufacture hierarchies of privilege and value; the racist, ableist, and self-legitimizing mentalities it gives rise to naturalize their privilege by appealing to elements in this network of confused

\footnotetext{
${ }^{6}$ Hughes, "Civilizing Modernity and the Ontological Invalidation of Disabled People," 17.

${ }^{7}$ Rowe, "Introduction," xiii.
} 
binaries. A leib/körper divide that separates the living from the living, and in doing so invalidates disabled bodies, becomes thinkable only in and through this network of imbricated binaries.

Extreme reactions to soundsinging frequently come in the form of speech acts that critique soundsingers by comparing them with bodies the speaker deems incapable. Midway through Paul Dutton's set at Hart House he told a story of an encounter with a screener for potential guests of one of Peter Gzowski's interview programs for the Canadian Broadcasting Corporation. This screener asked Dutton to read some of the material he might perform on the program if he appeared. He read a piece called "For the Letter That Begins Them All, H (for bp)," which begins semantically, gradually becomes vocables, and then shifts into a greater level of abstraction, featuring a series of controlled, sustained egressive and ingressive bands of complex vocal sound. The screener's response, Dutton explained, was: "I thought you were dying."

Example 2: Paul Dutton performing his poem "For the Letter That Begins Them All, H (for bp)" View at: http://dx.doi.org/10.3998/mp.9460447.0010.204

If we take the screener's comment as a straightforward observation about resemblance, "I thought you were dying" can be heard as another way of saying "I am only used to hearing this category of sound when I encounter someone in pain." Such a statement doesn't amount to a gesture of elimination or correction or contain a valuation of Dutton's sounds. However, this may be an inadequate translation, one that fails to get at a valuation intended by the original comment. Hughes' discussion of the structure of ableism helps suggest that a more accurate translation may be: "I expected your performance to symbolize leib rather than körper and your performance failed to meet that expectation." Such a comment implies a hierarchy of value, marks Dutton's performance as lacking in value, and amounts to an attempt to correct his violation of a symbolic order.

The ethnomusicological background of my work prompts me to be wary of putting words in the mouths of listeners. I realize that this type of "translation" should not be taken lightly. However, the critical theoretical imperative in my work and my experience as a performer periodically exposed to these types of comments both compel me to risk a theorization that seeks to uncover the subtexts that lie beneath them.

We can probably safely assume that the screener's words were not intended as a compliment; it likely wasn't the dignity of a state of pre-death or the profundity or intensity that might be experienced by someone aware their life is about to end that she intended to invoke. More likely, the response amounted to an ableist assessment of the dying body as one that has lost control, as one that involuntarily wheezes in pain, one that has become incapable. The association of the dying body with körper rather than leib betrays an ableist assessment of what it means to be in the transitional phase between life and death. Associating the sounds of pain with what Hughes calls an ontological deficit, a state of less-than-total human subjectivity, is an ableist valuation that oversteps the authority of any true distinction between leib and körper. And, it bears repeating, these self-privileging forms of valuation are fundamental to the ideological structure of modernity. Her invocation of the dying body in response to Dutton's performance was likely an attempt to mark his practice as lacking due to her assessment it did not symbolize lieb or the other privileged sides of modernity's binaries. The virtuosic and controlled sounds he employed were either not recognized as such, or, were recognized but refused. It is likely the screener's sense of Dutton's symbolic violation led her to ignore the differences between involuntary 
vocalization and Dutton's performance and to attempt to correct him by performing her assertion that these sounds belong in bodies that are unlike Dutton's, and, by extension, unlike her own.

If the screener's comment was merely an observation of resemblance, it is a highly reductive comparison that fails to take into account many of the qualities of both Dutton's performance and that of the cries of pained individuals. It seems the comment's intended function was to invoke bodies in a state of pre-death as a capital O Other along the lines of the leib/körper divide and to warn Dutton that engaging in such sonic practices threatens his access to the privileged side of that symbolic border. As such, it would represent a strategy of elimination or correction. Like much of Dutton's audience at Hart House, this screener was likely expecting speech when she asked Dutton to read. Perhaps she was even expecting a kind of heightened speech, the refined speech of someone whose life's work demands they speak often in public. Texts like Joni Wilson's The Voice of Success: A Woman's Guide to a Persuasive and Powerful Voice or Dr. Morton Cooper's Winning with Your Voice, remind us that voices can be deployed in ways that generate an image of perfection. But if we can "win" with our voices, it follows that we can also lose with them. Given the qualitative differences the screener overlooks, we can theorize that the expectation of the screener for a voice that signified perfection was not met; her invocation of a dying body was thus not merely about resemblance, it was an unconscious or quasi-conscious attempt to mark Dutton's voice as imperfect or disabled. It was, in other words, a speech act intended to discourage the exercise of that imperfect vocality. Though speech acts may amount to relatively mild attempts at correction or elimination, this particular listener had the power to exercise a greater and more immediate form of control over the audible public sphere. To wit: Dutton did not end up appearing on Gzowski's program.

Hughes writes:

It is important to understand ableist disgust as an emotion that attests to the failure of nondisabled people to fully recognise their own vulnerabilities and imperfections particularly as these relate to their mortal selves and to the death and decay that is the fate of all. Although it appears as an aversion to "the other," it is a form of self-aversion or a means by which we hide from the bodily basis of our own humanity.

Fundamental to disability studies is this notion - that the projection of inadequacy onto bodies of disabled Others is a part of a larger imperative placed on subjects under modernity to construct themselves as civilized, rational progress-makers. This act is accomplished relationally, by marking Others as static, primitive, incapable, and imperfect. The screener's need to project incapability onto Dutton's vocal performance amounts to an attempt to distance herself categorically from Dutton following a performance that articulated the human body with sounds that failed to signify to the screener a clear opposition between the various poles of modernity's binaries. Dutton's body became transformed by the sounds he produced into an unstable sign-visually a categorical equivalent to the screener's own sense of herself and her belongingness to the privileged side of modernity's great divide, yet sonically in violation of a symbolic order that places limits on what kinds of human vocal sound are capable of signifying the fully human. Stated differently, a disability studies approach encourages us to theorize the process generating her speech act as a multi-stage process. The first stage of this quasi-conscious process is a moment of recognition of her categorical equivalence with Dutton's human body. Next comes an articulation or connection of Dutton's sounds with the image of Dutton's body. Following this comes a recognition that Dutton's sounds are violating her expectation that vocal performances symbolize the "positive" categories of

\footnotetext{
${ }^{8}$ Hughes, 23.
} 
modernity's imbricated binaries. In other words, she quasi-consciously recognizes what she perceives to be a symbolic dissonance between Dutton's physical body and the vocalic body he is projecting. ${ }^{9}$ Then comes recognition that Dutton's body is now being articulated with the "negative" sides of modernity's binaries, which comes alongside a remembrance of her recognition of her own categorical equivalence with Dutton. Now, however, this equivalence acts to mark her body with the characteristics of the "negative" side of the modernity's binaries; it threatens rather than enhances her own desire to locate herself on the "positive" side of modernity's divide. With recognition of Dutton as threat comes an impulse to eliminate or correct this threat and to protect her illusory denial of her own human vulnerabilities and fallibility. In this case, this impulse leads to a speech act that attempts to correct Dutton by marking his performance as that of an abject, incapable Other. The invocation of the dying Other amounts to a reassertion of the comforting and false polarity of modernity after a temporary breakdown of that structure instantiated by Dutton's articulation of his own human vocal sounds with his human body. It acts to mark the performance as invalid in an attempt to prevent it from recurring and at the same time to invoke an Other the screener could perform her imaginary distance from, projecting the presence of vulnerability and frailty on the Other as a means of removing it from the self. In other words, this speech act was an attempt to restore a symbolic order Dutton's performance momentarily disturbed.

Hughes points to Giorgio Agamben and Martin Heidegger's insistence that the human-animal divide is the base reification of modernity's Othering processes when he writes:

The hypostatisation of reason traps disabled people in the cusp of the human-nonhuman/animal divide which is, according to Giorgio Agamben (2004), the fundamental division that underpins the very possibility of politics. The world of man is 'open to formation' intentional and free. By contrast, the animal is 'poor in the world,' captivated by dependency on its instinctual armoury (Heidegger, 1995). ${ }^{10}$

More frequent than invocation of the dying is the categorization of the human sounds of soundsinging as "animal" sound. It is quite common for listeners to come up to (sound)singers after a show and announce that the music sounded like "dog barking" or "pig squealing." 11 The centrality of the human/animal divide to the ideologies of modernity suggests that these comments also should not be taken as mere observations of resemblance; it suggests that in many instances of their appearance they need to be contextualized within this larger process of Othering under modernity and revealed to be highly related to the logic of ableism. Though the practices of some soundsingers have been informed by mimetic encounters with animal sounds and some soundsingers actively and intentionally imitate animal sound as part of their work, these kinds of comments appear whether or not the sounds of soundsinging actually bear intentional or unintentional resemblance to animal sound. The intentions behind such comments might vary, but in many instances they amount to tools of elimination or correction.

Another common speech act that often emerges is the suggestion that soundsinging is purposeless in a way that other music making is not. In an interview I conducted with her in October 2013, Montreal-based singer Joane Hétu explained:

\footnotetext{
${ }^{9}$ For a discussion of the concept of vocalic bodies, the notion that to hear a voice is always to imagine a body, see Connor, Dumbstruck, 35-37.

${ }^{10}$ Hughes, 24.

${ }^{11}$ Both of these terms, as well as a range of other invocations of animal sound, can be found as responses to videos of Yoko Ono's vocal work on youtube on the following pages: www.youtube.com/watch?v=EaCKKHcpf0w and www.youtube.com/watch?v=HdZ9weP5i68.
} 
I don't know why with samplers, electric guitars, with a lot of instruments you can do heavy sounds, but with voice people turn away. When the turntable does this same sound it's nice for them, but when I make it they ask: why are you doing this kind of sound with your voice? ${ }^{12}$

Though some listeners might ask this question with genuine curiosity, in most cases the question is another form of correction-the question "why are you doing this?" is a way of asserting that soundsinging is not a justifiable practice, or that it lacks purpose. Of course, the binary of purposeful/purposeless is yet another dichotomy whose poles become charged with valuation through its association with leib/körper and the other imbricated binaries of modernity. We must recognize that many of these reactions could be motivated as much by the absence and expectation of other symbolically charged forms of speech and song than by the kinds of sounds that did appear. These incidents seem to point us towards forms of symbolic labor that unfold in the service of the myths of modernity when bodies perceived to be fully human produce vocal sounds thought to symbolize ideals of human perfection. What may make the sounds of soundsinging feel purposeless is their failure to do the kinds of work other forms of speech and song do in reasserting modernity's symbolic order. One essential lesson this discussion leads us to is that dominant forms of speech and song are, at times, functioning to symbolically undergird the logic of modernity in ways we do not often acknowledge.

Hughes argues that modernity compels society to remove disabled bodies from "polite society so that it can realize the hygienic utopia inscribed in the civilising process." 13 The frequent corrective reactions soundsingers have received from listeners in various contexts have made it clear that this same utopia is not complete with imperfect vocal sounds publicly audible. The diverse but interconnected ways listeners have acted to correct soundsingers reveal that invocations of the animalistic, the uncontrolled, the incapable, the purposeless, are all translatable into to the comment: "I expected your performance to symbolize leib rather than körper and your performance failed to meet that expectation." All of these binaries are part of the same ideological construct and are dependent upon one another for the authority they require to function. The positioning of the animal as a category distinct from and lesser than the human requires a process of valuation that marks the human as capable of purpose in a way other animals are not. The same is true of a hierarchy of value that imagines the healthy body to have greater purpose than the dying body or differently abled bodies to be greater than one another, despite the life that continues to course through each of them. Though there is a clear distinction to be made between the living body and the dead body, the association of the leib/körper divide with modernity's other binaries enables the confusion that permits it to successfully overstep the conventional domain of that division, ascribing qualities of one category into a subset of the other. It falsely projects the qualities of the dead body on living bodies, justifying symbolic networks founded on hierarchies of valuation. Living human bodies that have not yet died are not dead flesh and they are no more lacking in "purpose" than any other body. To make such a claim is to forward an ableist conceit. Despite modernity's claims to the contrary, körper has no authority when it is treated as a question of degree. As the leib/körper binary oversteps its domain of authority to project the idea of mere flesh onto the living, it helps to naturalize the notion that the past can somehow be present within the present, reinforcing the primitive/civilized binary and the logic of modernity which becomes imaginable through confusion and reification of these binaries. Modernity's binaries feed into, mutually reinforce, and

\footnotetext{
${ }^{12}$ Tonelli, personal interview with Joane Hétu, Montreal, Canada, October 30, 2013.

${ }^{13}$ Hughes, 26.
} 
utterly depend on one another to constantly renew and reassert their individual authority and that of the overall discursive formation of modernity.

Acknowledging the interconnectedness of these binaries helps us to recognize that invocations of animals and cries of pain in response to the sounds of soundsinging are more than harmless observations about resemblance. Rather, they are invocations of a broader network of associations that serve to distance anxious individuals from their own vulnerabilities and imperfections by asserting modernity's self-legitimating logic. The interconnectedness and interchangeability of these binaries becomes even more apparent when speech acts made in response to soundsinging performances evoke more than one binary at a time. When listeners respond to soundsinging performances with comments like "She sounds like a hippo giving birth," or "What a wounded yak," or "A good rendition of the sound of someone jumping or being pushed off a roof! Maybe a cat!," they revealingly invoke both human/animal and the ableist binary that marks bodies imagined to be in states of pain or compromised states of selfcontrol as belonging to the körper end of leib/körper. ${ }^{14}$

To some degree, soundsingers have gravitated to the sounds of soundsinging as a means of promoting a politics of inclusion that opposes the exclusory logic of modernity. Jaap Blonk explains that in the world of soundsinging he "think[s] there is a political side to the terms that no sound can ever be excluded from a performance." $" 15$ This statement attests to a perception that politics is being enacted in the spaces of soundsinging through a radical form of inclusion. It attests to a perception that other spheres operate through exclusion of certain types of sounds and the sounds excluded there are finding visibility in the space of soundsinging. While Blonk's perception may ignore forms of exclusion that might arise in spaces of soundsinging, this can be left for another discussion. What his perceptions point to here is that inclusivity may itself be a significant aspect of the threat that soundsinging poses to those that would correct it, alongside the creation of perceptions that the human-animal divide is being revealed as false, the vulnerability of all bodies is being affirmed, and instrumentality and reason are being discarded. Modernity's logic cannot be sustained when all voices are permitted to sing and Blonk suggests that this is a defining characteristic of the practice of soundsinging. A listener once said to me after a show: "If there are no standards, no order, everything falls apart." Of course, what really falls apart through a radical politics of inclusion are structures of privilege. In his Homo Sacer, Giorgio Agamben theorizes that Western politics itself emerged in and through the exclusion of what he calls bare life, a concept situated in opposition to the "good life" offered by the political and which Agamben associates with voice, which itself he sees as excluded in and through language. ${ }^{16}$ The patterns of exclusion, or inclusive-exclusion as he refers to it, playing out in the musical contexts I describe here are recursions of a fundamental exclusion upon which modern Western politics and privilege were founded.

It is interesting to note in the context of this discussion the extreme lengths many soundsingers go to make their practices inclusive not just in terms of sounds, but in terms of who is permitted to participate and the ethico-aesthetic principles that govern that collaboration. A number of soundsingers make substantial efforts to foster spaces in which others can explore their voices in an environment where unconventional vocalization won't be policed. One example of this is the Feral Choir component of Phil Minton's practice. His Feral Choirs are groups of singers and "non-singers" that come together

\footnotetext{
${ }^{14}$ Each of these comments was posted on Youtube (www.youtube.com/watch?v=HdZ9weP5i68) in response to a (sound)singing performance given by Yoko Ono at the Museum of Modern Art. Retrieved October 15, 2014

${ }^{15}$ Tonelli, personal interview with Jaap Blonk, Los Angeles, June 18, 2004.

${ }^{16}$ For more on the devocalization of logos see Adriana Cavarero, For More Than One Voice.
} 
to work with him in various locations around the world for short periods of time, usually involving one or more workshops and a performance. The use of the term "feral" is a gesture of re-appropriation; someone who had seen him sing responded by calling him a feral singer-yet another example of the invocation of the animalistic in response to soundsinging. Given the frequency with which such comments are intended as an insult, Minton's adoption of the term does amount to a reclamation of the term that flips the script of vocal animality. Minton's appropriation of the concept of the feral points to the ways in which the relationship of the voice to modernity is like a process of domestication. Of course, the concept of domestication can come in an ideological and value-laden form that romanticizes a supposed state of nature and positions the "domesticated" as inferior. On the other hand, there may be a less ideological, more concrete distinction to be made between the activities of an animal who is dependent upon human society and the activities of one who is not. Similarly, there may be a concrete distinction between those who self-police vocally, strictly limiting the forms their vocal explorations can take, and those who try, however imperfectly, to eschew such proscriptions in their improvisations.

In a public interview I conducted with Minton he explained:

I was invited first in a music college in Sweden, to do [an improvising choir]. It was with trained singers, mostly. And, I wasn't really that happy with it in the early days. But, then I got invited to do some in housing projects in France ... The actual choral results weren't that impressive; the actual sound of the singers, it wasn't exactly what I wanted, how I was hearing it in my head. But, afterwards the people were so enthusiastic and loved it so much. They said: "Oh, we had such a great time. It was the first time we'd ever been onstage and sung and used our voices." And, it really literally brought me to tears and I thought I really want to do this more in lots and lots of different situations. Now, the aesthetic idea of trying to get a group of singers to sound like some preconceived idea I had in my head, that's gone. ${ }^{17}$

Here, again, we have a (sound)singer placing inclusivity and aesthetic openness ahead of a particular aesthetic ideal, refusing to dictate what sounds will be included and excluded in the choir. The visibility and audibility of both sounds and voices that have lacked visibility and audibility becomes the motivating factor in continuing the work. Another improvising vocalist, Maggie Nicols, who has also devoted much of her time over the last forty-five years to organizing inclusive gatherings for vocal and vocal/instrumental improvisation, speaks of this as the prioritization of social virtuosity:

John [Stevens] was the master of mixed ability. Thank you John. I have to give him credit, because John changed my life. John showed me that. He was the master of mixed ability. He could take someone that had been playing for sixty years and someone who had never played and his pieces created excellence. And, it wasn't patronizing. It was always the professional musicians who often didn't grasp his pieces at all. I've done the Click Piece with people with learning differences and they often get it so much better than musicians and they have fun with it. It's so democratic, isn't it? And isn't that beautiful? And it is what I call social virtuosity. It's something I feel very passionate about. ${ }^{18}$

\footnotetext{
${ }^{17}$ Tonelli, public interview with Minton. See Tonelli, "Social Virtuosity and the Improvising Voice."

${ }^{18}$ Tonelli, personal interview with Maggie Nicols, Guelph, Canada, June 25, 2014. For more on Nicols' concept of social virtuosity see Cowley, "Open to the Muse: the Vocal and Social Art of Maggie Nicols," or Tonelli, "Social Virtuosity and the Improvising Voice." Or, better, visit The Gathering, a regular open, inclusive improvisation-centered get-together founded by Nichols that occurs in London and Carmarthenshire, Wales; see facebook.com/groups/TheGatheringFreeImprovisation for more information.
} 
Example 3: Phil Minton and his Feral Choir

View at: http://dx.doi.org/10.3998/mp.9460447.0010.204

Example 4: Maggie Nicols and Contradictions

View at: http://dx.doi.org/10.3998/mp.9460447.0010.204

The structure of modernity is based on exclusion. Might the threat soundsinging poses to those that act to correct or eliminate it be understood on some level as the threat of a symbolization of total inclusion, as the threat of a vocal practice that rejects existing structures of exclusion in the field of vocal practice and, in so doing, inhibits some of the symbolic functions those structures serve? While soundsinging may or may not realize in actuality the kinds of inclusion to which some of its practitioners aspire, this aspiration itself deserves be acknowledged alongside our discussion of the ways listeners attempt to correct soundsingers and eliminate soundsinging. Placing these discussions together foregrounds conflicts currently being played out in a variety of musical domains. These conflicts affect the lives of performers and listeners and have broader implications in and through their connections to other battles over forms of social exclusion that hinge in similar ways on the logic of modernity. Revealing these connections might allow us to consider our own responses to vocal practices more generally and think more deeply and critically about the hidden structures that govern our own processes of valuation.

Voices are powerful. They comfort and they threaten. The example of soundsinging is valuable, in part, because it makes visible and audible the hidden labor that the vocal materiality of speech and song performs, labor that often enforces modernity's species-ideals for the voice. As the bodies of the three listeners I described at the outset of this essay demonstrate, reactions to the unconventional vocality of soundsinging vary. However, the range of reactions-from invocations of the dying body, to charges of purposelessness and irrationality, and anxiety about policing the border of the human-animal dividesuggests that nonstandard vocal materialities such as soundsinging are more than just "difficult listening": they threaten the exclusionary logic upon which modernity is based. Listeners who fail to hear intention and control in the abstract vocal work of a singer/poet like Paul Dutton, who hear only their anxiety telling them that this is death, this is meaningless, this is animalistic, are likely also listeners used to using voices to prop up their own ableist sense of superiority, listeners whose ontological insecurity drives aspects of their musical judgment. Steven Connor observes that "all too often, the voice is experienced as more-than-body, as the body projected, perfected." ${ }^{19}$ Rather than simply having neutral reactions to soundsinging, these listeners feel compelled to perform gestures of correction or elimination to protect the symbolic processes that give them access to these exclusory fantasies of invulnerability and superiority. The important work being done in the field of disability studies provides us with a compelling theory as to why this might be the case.

As vocalists, we cannot control the meanings that listeners attach to the vocal sounds we produce, but we can control the sounds we choose to make, and we can cultivate an awareness of the kinds of meaning that emerge when we sing. We can consider the ways our vocal sounds serve or confound ideologies that imagine progress and perfection by reducing and dehumanizing various others. If soundsinging performances are frequently perceived as violations of the symbolic order of modernity,

${ }^{19}$ Conner, Beyond Words, 17. 
might it not follow that dominant normative forms of speech and song work at times to symbolically undergird and naturalize the exclusory logic of modernity and the racist and ableist manifestations of that logic? In other words, does singing or speaking in a manner constructed as "proper" by listeners who would act to correct or eliminate soundsinging fuel symbolic reaffirmations of self by those empowered by modernity's racist, ableist logics? If our vocal practices are subtly reinforcing ableist ideals, we might be doing important work by choosing, now and then, to defy expectation. Perhaps we all could inject a bit more sound in our singing.

Example 5: Gabriel Dharmoo, Maggie Nicols, Phil Minton, and Chris Tonelli

View at: http://dx.doi.org/10.3998/mp.9460447.0010.204

\section{Works Cited}

Agamben, Giorgio. Homo Sacer. London: Reaktion Books, 1998.

Blonk, Jaap, interview with the author, Los Angeles, California, June 18, 2004.

Cavarero, Adriana. For More Than One Voice. Stanford: Stanford University Press, 2005.

Connor, Steven. Dumbstruck: A Cultural History of Ventriloquism. Oxford: Oxford University Press, 2000. http://dx.doi.org/10.1093/acprof:oso/9780198184331.001.0001.

Connor, Steven. Beyond Words: Sobs, Hums, Stutters, and Other Vocalizations. London: Reaktion Books, 2014.

Cooper, Morton. Winning with Your Voice. Chatsworth: Wilshire Book Company, 1996.

Cowley, Julian. "Open to the Muse: The Vocal and Social Art of Maggie Nicols." Musicworks 101 (Spring 2008).

Dutton, Paul. "Sonosyntactics: Musicoliterary Innovation." University of Toronto, Hart House, Toronto, Canada. 7 February 2014. Public Poetry Reading as part of the endless need to begin: Re: Turning to the Canadian Long Poem Symposium.

Dutton, Paul. Liner notes to Mouth Pieces. OHM éditions/Avatar, 2000.

Hétu, Joane, interview with the author, Montreal, Quebec, October 30, 2013.

Hughes, Bill. "Civilising Modernity and the Ontological Invalidation of Disabled People." Disability and Social Theory: New Developments and Directions. New York: Palgrave Macmillan, 2012. http://dx.doi.org/10.1057/9781137023001_2.

Minton, Phil. Public Interview by Chris Tonelli. Symposium on Voice, Agency, and Improvisation. Macdonald Stewart Art Centre. Guelph, ON, Canada, June 26, 2014.

Nicols, Maggie, interview with the author, Guelph, Ontario, June 25, 2014.

Rowe, John Carlos. "Introduction." Racial Blackness and the Discontinuity of Western Modernity. Chicago: University of Illinois Press, 2014.

Sutherland, W. Mark. “'A sound burst out of me': An Interview with Paul Dutton.” Jacket2. February 28, 2014. http://jacket2.org/interviews/sound-bursts-out-me/.

Tonelli, Chris, Phil Minton, and Maggie Nicols. "Social Virtuosity and the Improvising Voice: Phil Minton and Maggie Nicols Interviewed by Chris Tonelli." Critical Studies in Improvisation 10:2 (2015).

Wilson, Joni. The Voice of Success: A Woman's Guide to a Persuasive and Powerful Voice. New York: Amacom, 2009. 


\begin{abstract}
Soundsinging is one name for the practice of making music using an idiosyncratic palette of vocal and non-vocal oral techniques. This paper is concerned with the reception of soundsinging and, more specifically, with listeners whose reactions to soundsinging involve attempts to contain the practice. To theorize these reactions, I draw on the work of disability studies scholars and their concept of ableism. Ableists are subjects whose insecurity about their own mortality manifests in a compulsion to eliminate or correct bodies they feel do not represent a speciesideal. I draw on interviews I have conducted with (sound)singers like Paul Dutton, Joane Hétu, and Jaap Blonk, as well as on my own experiences as a soundsinger, to point to the ways in which the behavior and containment strategies of listeners exposed to soundsinging often resemble those experienced by disabled individuals. Both disabled individuals and soundsingers experience ableist speech acts that mark them as animalic, incapable, and lacking instrumentality. Ableism is one manifestation of the construct of modernity, a construct whose structure requires a positioning of some Other as uncivilized or imperfect in order to posit the existence of progress and perfection. Ableists' investment in certain bodies and voices as signifiers of perfection interferes with their ability to hear soundsinging as anything other than a violation of that ideal. Exposing the existence of ableist listening can help us understand not only what kinds of aesthetic and political processes unfold during soundsinging; perhaps more crucially, it reveals the hidden processes that the ableist's vocal ideal enables and encourages.
\end{abstract}

